\title{
Human Keratinocytes Are a Major Source of Cutaneous Platelet-derived Growth Factor
}

\author{
John C. Ansel, Jay P. Tiesman," John E. Olerud, ${ }^{3}$ James G. Krueger, ${ }^{\star}$ Jeffrey F. Krane, ${ }^{\star}$ David C. Tara, Gary D. Shipley, ${ }^{\star}$ \\ Debra Gilbertson," Marcia L. Usui," and Charles E. Hart" \\ Portland Veterans Administration Medical Center and Oregon Health Sciences University, Portland, Oregon 97201; * Department of Cell \\ Biology and Anatomy, Oregon Health Sciences University, Portland, Oregon 97201; ${ }^{\ddagger}$ The Rockefeller University, New York 10021; \\ ${ }^{\S}$ Division of Dermatology, University of Washington Seattle, Washington 98195; and "ZymoGenetics, Inc., Seattle, Washington 98105
}

\begin{abstract}
PDGF has been implicated as one of the principal mitogens involved in cutaneous wound healing. While it has been previously reported that both platelets and monocytes are a source of PDGF in human dermal wound repair, the production of PDGF by human keratinocytes has not yet been described. In this manuscript, we report the production of PDGF by cultured human keratinocytes. Both PDGF $A$ and B chain mRNA can be detected in cultured cells. While only PDGF-AA polypeptide is found in significant levels in keratinocyte-conditioned culture media, all three PDGF isoforms ( $A A, A B$, and $B B$ ) are present in detergent-solubilized cell extracts. No evidence of PDGF receptor expression was observed in cultured keratinocytes when analyzed for either mRNA levels or polypeptide expression, suggesting that PDGF does not play an autocrine role in keratinocyte growth. Analysis of cryosections of human cutaneous wounds by immunostaining for PDGF showed that both PDGF $A$ and $B$ chain is constitutively expressed in normal epidermis, as well as in newly reconstituted wound epidermis. No evidence for PDGF receptor polypeptide expression in the epidermis was detected by immunostaining of cryosections. ( $J$. Clin. Invest. 1993. 92:671-678.) Key words: platelet-derived growth factor • PDGF receptors • keratinocyte • wound healing • epidermis
\end{abstract}

\section{Introduction}

Keratinocytes have been demonstrated to produce a wide range of cytokines and growth factors, including IL-1, IL-3, IL-6, IL-8, IL-10, colony-stimulating factors, $\mathrm{TNF}_{\alpha}, \mathrm{TGF}_{\alpha}$, $\mathrm{TGF}_{\beta}$, fibroblast growth factor, IL-1 receptor antagonist, and amphiregulin (reviewed in reference 1). These cytokines are thought to play an important role in mediating inflammatory and proliferative processes in the skin. To date the epidermis has not been considered a source of PDGF in man. In the present study we examined the possibility that normal human keratinocytes and normal epidermis are able to synthesize and secrete PDGF.

PDGF is the principle mitogen in serum for cultured cells of mesenchymal origin, including fibroblasts, and smooth muscle cells (reviewed in reference 2). PDGF is a disulfidelinked dimer of two chains termed A chain and B chain, which

Address correspondence to Charles E. Hart, Ph. D., ZymoGenetics Inc., 4225 Roosevelt Way NE, Seattle, WA 98105.

Received for publication 17 December 1992 and in revised form 8 March 1993.

The Journal of Clinical Investigation, Inc.

Volume 92, August 1993, 671-678 can form dimers of PDGF-AA, PDGF-AB, and PDGF-BB. All three of the dimer forms have been identified from natural sources and shown to be biologically active $(3,4)$. The A and B chains share $\sim 60 \%$ amino acid sequence identity, including eight conserved cysteine residues in the mature coding sequence. The biological activities of PDGF are mediated via binding to cell-surface receptors. Two PDGF receptors have been identified, termed alpha and beta $(5,6)$. The genes for the two receptors code for transmembrane proteins which contain split tyrosine kinase domains within the cytoplasmic portion of the molecules (7-11). Similar to the PDGF ligands, dimerization of the two receptors is thought to be required for the generation of high affinity binding sites. Receptor dimerization appears to be mediated through ligand binding such that the isoform of PDGF presented to the cell will determine the types of receptor dimers formed $(12,13)$. The three potential PDGF receptor dimers have different ligand binding specificities for the three forms of PDGF with alpha/alpha dimers binding PDGF-AA, AB, and BB, alpha/beta dimers binding PDGF$\mathrm{AB}, \mathrm{BB}$ and beta/beta dimers binding only PDGF-BB (reviewed in reference 14 ).

Due to the various biological activities stimulated by PDGF on cells in culture, PDGF has been implicated as one of the primary components involved in stimulating dermal wound repair. In addition to its mitogenic activities, PDGF is a chemoattractant for fibroblasts (15), and monocytes and neutrophils (16). PDGF has also been shown to stimulate increased levels of extracellular matrix production by fibroblasts in culture (17). Recent studies have shown that the topical application of PDGF-BB to wounds made on diabetic mice, which have impaired wound healing capabilities, stimulates both accelerated wound closure and the development of thickened granulation tissue (18). PDGF-BB treatment has also been recently shown to accelerate the rate of wound healing in humans when added to chronic pressure ulcers (19).

Platelets and macrophages have been described as two of the principle sources of PDGF at the site of a cutaneous wound. In this manuscript we describe the expression of PDGF $A$ and $B$ chain mRNA and protein in cultured human keratinocytes. We additionally show that PDGF is produced in normal human epidermis as well as at sites of acute tissue repair in wounded skin. These results demonstrate that the epidermis of human skin is a third major source of PDGF for cutaneous wound healing. This also suggests that the epidermis may play a direct role in dermal repair processes by the production of PDGF and its subsequent actions on target cells within the dermis.

\section{Methods}

Growth factors, antibodies, and cultured cells. PDGF AA and BB were generated in a yeast expression system and purified to homogeneity as 
previously described (20). Protein concentrations were determined by amino acid analysis. IL- $1_{\alpha}$ and $\mathrm{TGF}_{\beta}$ were purchased from Genzyme Corp. (Cambridge, MA) and a gift of Dr. Bruce Magan (Department of Cell Biology and Anatomy, Oregon Health Sciences University, Portland, $O R$ ), respectively.

Anti-PDGF monoclonal antibodies were generated and characterized as previously described (3). The ligand binding specificity for the anti-PDGF monoclonal antibodies are as follows: 127.222 (PDGFAA), 127.822 (PDGF-AA), 127.573 (PDGF-AA and AB), 120.121 (PDGF-BB), 120.311 (PDGF-BB), 172.511 (PDGF-BB), 121.611 (PDGF-BB and AB). Rabbit anti-PDGF $A$ chain IgG and rabbit antiPDGF B chain IgG polyclonal antibodies used in the ELISAs and as neutralizing antibodies in the mitogenesis assay (described below) were generated as previously described ( 3 ) by immunizing rabbits with purified recombinant PDGF-AA or PDGF-BB, respectively. The monoclonal antibodies and the rabbit anti-PDGF IgG antibodies were isolated by protein A-Sepharose (Pharmacia Fine Chemicals, Piscataway, NJ) chromatography. Affinity-purified rabbit anti-PDGF A chain and affinity-purified rabbit anti-PDGF B chain polyclonal antibodies, used for immunostaining of human tissue, were isolated by passage of the serum over a Sepharose-4B column coupled with either PDGF-AA or PDGF-BB. The bound antibody was eluted with $0.1 \mathrm{M}$ citrate, $\mathrm{pH} 3.0$, then the isolated antibody cross-adsorbed on the opposite ligand column to remove any antibody cross-reacting with both PDGF A and B chain. The affinity isolated rabbit anti-PDGF $A$ chain and $B$ chain antibodies recognize $P D G F-A A$ and $A B$, and $B B$ and $A B$, respectively, with $<1 \%$ cross-reactivity to the opposite homodimer. PDGF-AA and BB were coupled to $\mathrm{CnBr}$-activated Sepharose-4B (Pharmacia Fine Chemicals) as described by the manufacturers at a ratio of $5 \mathrm{mg} / \mathrm{g}$ of dry gel.

The generation and characterization of anti-PDGF receptor monoclonal antibodies PR7212 (beta receptor) and PR292 (alpha receptor) have been previously described $(21,22)$. Monoclonal antibody 169.522 was produced by fusing NS-1 myeloma cells with spleen cells isolated from mice immunized with chimeric PDGF receptor molecules containing the extracellular domain of the human PDGF alpha receptor and the constant domains of human immunoglobulin heavy and light chains (Hart, C. E., and D. Gilbertson, unpublished data). This antibody, which specifically recognizes the extracellular domain of the PDGF alpha receptor, was characterized for receptor binding specificity by the same criteria as used for antibodies PR7212 and PR292 (21, 22).

Human keratinocytes were initially isolated from explants of newborn foreskins. The cells were cultured in either keratinocyte basal medium $(\mathrm{KBM})^{1}$ or keratinocyte growth medium $(\mathrm{KGM})($ Clonetics Corp., San Diego, CA), containing $0.15 \mathrm{mM} \mathrm{Ca}^{2+}$, as described in specific sections of Methods. Subconfluent cultures of keratinocytes, ranging between 75 and $95 \%$ confluent, were used for all of the studies described below.

$P D G F$-specific ELISAs. Sandwich ELISAs were used to detect and quantitate the levels of the individual PDGF isoforms (AA, AB, BB) essentially as described (3). Anti-PDGF monoclonal antibodies specific for either the A or B chain of PDGF were added to 96-well microtiter plates at $5 \mu \mathrm{g} / \mathrm{ml}$ in coating buffer $\left(0.1 \mathrm{M} \mathrm{NaHCO}_{3}, \mathrm{pH} 9.0\right)$ for $18-24 \mathrm{~h}$ at $4^{\circ} \mathrm{C}$. The wells then incubated with ELISA B buffer (PBS, pH $7.2 ; 1 \%$ BSA, $0.05 \%$ Tween-80) for either $2 \mathrm{~h}$ at $37^{\circ} \mathrm{C}$ or overnight at $4^{\circ} \mathrm{C}$ to block nonspecific binding sites. The wells were washed twice then stored dry at $4^{\circ} \mathrm{C}$ until used. The coating antibodies used to detect the individual PDGF isoforms were 127.222 (PDGF-AA), 172.511 (PDGF-BB), and 121.611 (PDGF-AB). Test samples were added to the antibody coated wells for $2 \mathrm{~h}$, the wells washed, then incubated for an additional $2 \mathrm{~h}$ with either polyclonal rabbit anti-PDGF $\mathrm{A}$ chain antibody (127.222 and 121.611) or polyclonal rabbit anti-PDGF B

1. Abbreviations used in this paper: $\mathrm{KBM}$, keratinocyte basal medium; KGM, keratinocyte growth medium; OCT, Tissue-Tek O.C.T. embedding compound (Miles Laboratories, Inc.); TBS, Tris-buffered saline. chain antibody (172.511). The wells were washed, then incubated for 1 $h$ with horseradish peroxidase-conjugated goat anti-rabbit antibody (Tago, Inc., Burlingame, CA) diluted 1:2,000 with ELISA B buffer. The level of bound antibody was determined by the addition of reaction buffer $(0.1 \mathrm{M} \mathrm{Na}$ citrate, $\mathrm{pH} 5.0 ; 0.5 \mathrm{mg} / \mathrm{ml} o$-phenylenediamine dihydrochloride; $0.5 \mu \mathrm{l} / \mathrm{ml} 30 \% \mathrm{H}_{2} \mathrm{O}_{2}$ ) and the reaction product read in a Microplate reader (Bio-Tek Instruments, Winooski, VT) at 492 $\mathrm{nm}$. All incubations were done at $37^{\circ} \mathrm{C}$ unless noted and all washes done with ELISA C buffer (PBS, pH 7.2; 0.05\% Tween-80).

To obtain detergent solubilized cell extracts, cells were washed with PBS, then extracted with RIP buffer ( $20 \mathrm{mM}$ Tris- $\mathrm{HCl}$, pH. 8.0, 100 $\mathrm{mM} \mathrm{NaCl}, 1 \mathrm{mM}$ EDTA, $0.5 \% \mathrm{NP}-40,0.5 \%$ sodium deoxycholate, 10 $\mathrm{mM} \mathrm{Nal}, 1 \% \mathrm{BSA}$ ) on ice. The extract was centrifuged at $2,000 \mathrm{~g}$ to pellet cellular debris, and the supernatant was harvested.

Northern blot analysis. Cytoplasmic mRNA was isolated using the NP-40 lysis method as described by Mushinski et al. (23). Poly $\mathrm{A}^{+}$ RNA was obtained by two passages over oligo dT cellulose (Boehringer Mannheim, Indianapolis, IN). RNA samples ( $2 \mu \mathrm{g} /$ lane $)$ were electrophoresed on a $1 \%$ agarose-formaldehyde gel, transferred to nitrocellulose, and hybridized with ${ }^{32} \mathrm{P}$-labeled cDNA-probes. The PDGF A chain probe was a 1.3-kb EcoRI fragment that corresponds to the short version of the PDGF-A mRNA (24) and which was a gift from Christer Betsholtz (Uppsala University, Uppsala, Sweden). The B chain probe used was a PstI/XbaI 1.0-kb fragment which codes for the v-sis sequence (25) and which was a gift from Keith Robbins (National Institutes of Health, Bethesda, MD). The PDGF alpha receptor probe contains nearly the entire coding sequence and corresponds to bp $252 \rightarrow$ 3978 (11). The PDGF beta receptor probe contains the full length human cDNA and corresponds to bp $356 \rightarrow 5570(8)$. DNA probes were radiolabeled using the random hexamer method (26).

Immunostaining of normal human skin for PDGF. Cryostat sections of normal human skin were prepared on gelatin-coated slides and were postfixed with $10 \%$ buffered formalin for $10 \mathrm{~min}$. Sections were reacted with monoclonal antibodies $120.311,127.822,120.121$, and 127.573, using $0.25-1.0 \mu \mathrm{g} / \mathrm{ml}$ final concentrations. All antibodies, including those used for competition with purified antigen, were diluted in PBS containing $10 \mathrm{mg} / \mathrm{ml}$ BSA. Staining by 127.573 was competed by the addition of $1 \mu \mathrm{g}$ of purified PDGF-AA. No competition for 127.573 staining was observed with $10 \mu \mathrm{g} / \mathrm{ml}$ PDGF-BB. Staining by 120.121 was competed by $10 \mu \mathrm{g} / \mathrm{ml} \mathrm{BB}$. Antibody binding was visualized using an anti-mouse avidin-biotin complex kit (Vector Laboratories, Burlingame, $\mathrm{CA}$ ) and 3-amino-9-ethyl-carbozol as the chromagen.

Immunostaining of human wounds for PDGF. Wounds were created on legs of normal human volunteers using a Simplate-II bleeding time device (Organon Teknika, Durham, NC). Punch biopsies ( $4 \mathrm{~mm}$ ) were taken of the wounds, immediately frozen in embedding compound (Tissue-Tek O.C.T. [OCT]; Miles Laboratories, Inc., Elkhart, IN), and stored at $-70^{\circ} \mathrm{C}$ until cryosectioned $(8 \mu \mathrm{m})$. Sections were placed onto acid-washed $(1 \% \mathrm{HCl} / 70 \% \mathrm{EtOH})$ and $2 \%$ 3-aminopropyltriethoxysilane (Sigma Immunochemicals, St. Louis, MO)/acetone-coated slides. Sections were fixed in cold acetone for $5 \mathrm{~min}$, rinsed in $0.5 \mathrm{M}$ Tris-buffered saline (TBS) $3 \times 5 \mathrm{~min}$ each, then blocked for endogenous peroxidase in $0.3 \% \mathrm{H}_{2} \mathrm{O}_{2} / \mathrm{TBS}$ for $30 \mathrm{~min}$. The slides were rinsed $3 \times 5 \mathrm{~min}$ in TBS, serum blocked with $1.3 \%$ goat serum/TBS for $30 \mathrm{~min}$, and then stained for $1 \mathrm{~h}$ at room temperature with affinity-purified polyclonal rabbit anti-PDGF $A$ chain or rabbit anti-PDGF $B$ chain antibody. The antibodies were diluted with $0.1 \%$ BSA/TBS. The slides were rinsed $3 \times 5 \mathrm{~min}$ with TBS, blocked an additional $5 \mathrm{~min}$ with goat serum, then incubated with biotinylated goat anti-rabbit IgG (Vector Laboratories) for $30 \mathrm{~min}$. The slides were washed $3 \times 5 \mathrm{~min}$ with TBS, $1 \times 5$ min with normal goat serum, then incubated with streptavidin AH-biotin complex (Zymed Laboratories, Inc., South San Francisco, CA) for $30 \mathrm{~min}$ at room temperature. The slides were washed $3 \times 5 \mathrm{~min}$ with TBS, rinsed in $5 \mathrm{mM}$ Tris buffer for $5 \mathrm{~min}$, and subsequently developed with $2 \mathrm{ml} 0.12 \% 3,3^{\prime}$ diaminobenzidine (Sigma Immunochemicals) $/ \mathrm{H}_{2} \mathrm{O} ; 1.2 \mathrm{ml} \mathrm{H} \mathrm{H}_{2} \mathrm{O} ; 0.8 \mathrm{ml} 0.5 \mathrm{M}$ Tris buffer; $4 \mu \mathrm{l}$ of $30 \% \mathrm{H}_{2} \mathrm{O}_{2}$ for $20 \mathrm{~min}$. The slides were then rinsed in 0.5 
M Tris buffer for $5 \mathrm{~min}$, rinsed $3 \times 5 \mathrm{~min}$ in TBS and coverslipped using Glycergel (Dako Corp., Carpinteria, CA). Control sections were not exposed to primary antibody.

Immunostaining of wounded human skin for PDGF receptor. Materials and methods used for staining of sections for PDGF receptor were as above for PDGF immunostaining with the following exceptions. Slides were rinsed $3 \times 5 \mathrm{~min}$ with TBS before fixation to remove the OCT. The cryosections were fixed in $0.1 \%$ glutaraldehyde/PBS rather than in acetone. The sections were stained with primary antibody 169.522 (PDGF alpha receptor) or PR7212 (PDGF beta receptor). Secondary antibody used was biotinylated anti-mouse IgG made in horse (Vector Laboratories), and the serum block was done with $0.3 \%$ horse serum/TBS.

Analysis of PDGF mitogenic activity. Purified PDGF-AA and concentrated keratinocyte conditioned culture media were analyzed for mitogenic activity by the ability to stimulate $\left[{ }^{3} \mathrm{H}\right]$ thymidine incorporation into murine 3T3 cells essentially as described by Raines et al. (27). To generate keratinocyte-conditioned culture media, KGM was added to subconfluent monolayers of human keratinocytes for $48 \mathrm{~h}$. The media was harvested then concentrated 50-fold using a Centriprep-10 concentrator (Amicon, Beverly, MA). Dilutions of the media concentrate were made using fresh KGM. The concentrated media samples were added to the 3T 3 cells at $1 / 10$ th final vol. Dilutions of PDGF-AA were added to the cells at final concentrations of $5,1.25$, and 0.31 $\mathrm{ng} / \mathrm{ml}$. Monoclonal antibody 127.222, polyclonal rabbit anti-PDGF A chain, or polyclonal rabbit anti-PDGF B chain $(25 \mu \mathrm{g} / \mathrm{ml}$ final concentration) were added simultaneously to $3 T 3$ cells containing either 5 $\mathrm{ng} / \mathrm{ml}$ of pure PDGF-AA or to the undiluted media concentrate. The cells were incubated for $20 \mathrm{~h}$ with the test samples, the media removed, and the cells pulsed for $4 \mathrm{~h}$ with $\left[{ }^{3} \mathrm{H}\right]$ thymidine. The cells were washed with PBS, trypsinized, then harvested with a cell harvester (Wallac; LKB, Turku, Finland) and counted for $\left[{ }^{3} \mathrm{H}\right]$ thymidine incorporation in a Betaplate liquid scintillation counter (Wallac; LKB).

\section{Results}

$P D G F A$ chain and $B$ chain $m R N A$ expression. Monolayer cultures of normal human keratinocytes were analyzed for the expression of PDGF A and B chain mRNA by Northern blot analysis. Cells grown in KBM demonstrated elevated levels of constitutive expression of three sized transcripts of 2.8,2.3, and $1.9 \mathrm{~kb}$ for PDGF A chain mRNA (Fig. 1). Only trace levels of $B$ chain mRNA were detected in the KBM-cultured cells. The addition of $\mathrm{IL}-1_{\alpha}(10 \mathrm{ng} / \mathrm{ml})$ to the culture media for $12 \mathrm{~h}$ resulted in an increase in a 4.0-kb transcript for PDGF B chain with no corresponding increase in the level of $A$ chain mRNA. In contrast, an increase in the levels of both $A$ chain and $B$ chain mRNA were detected after the addition of $\mathrm{TGF}_{\beta}$ (10 $\mathrm{ng} / \mathrm{ml}$ ) to the cells for $12 \mathrm{~h}$.

Production of PDGF-AA, $A B$, and $B B$ polypeptide. To monitor the production of PDGF polypeptide by human keratinocytes, 24-h conditioned culture media was analyzed by ELISA for the presence of the three isoforms of PDGF (AA, $\mathrm{AB}, \mathrm{BB})$. The individual PDGF isoforms were detected and quantitated as previously described (3) using isoform-specific monoclonal antibodies as the catching antibodies in sandwich ELISA formats. Only PDGF-AA was detected in the conditioned culture media of cells grown in KBM (Table I), consistent with the detection of predominantly $A$ chain mRNA in these cells. Surprisingly, however, only PDGF-AA was de-

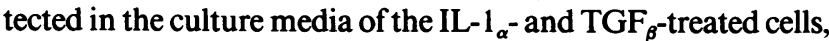
even though these cells express both PDGF A and B chain mRNA. IL- $1_{\alpha}$ treatment had essentially no effect on PDGFAA secreted while $\mathrm{TGF}_{\beta}$ caused an $88 \%$ increase in the level of PDGF-AA secreted into the culture media. In contrast to the

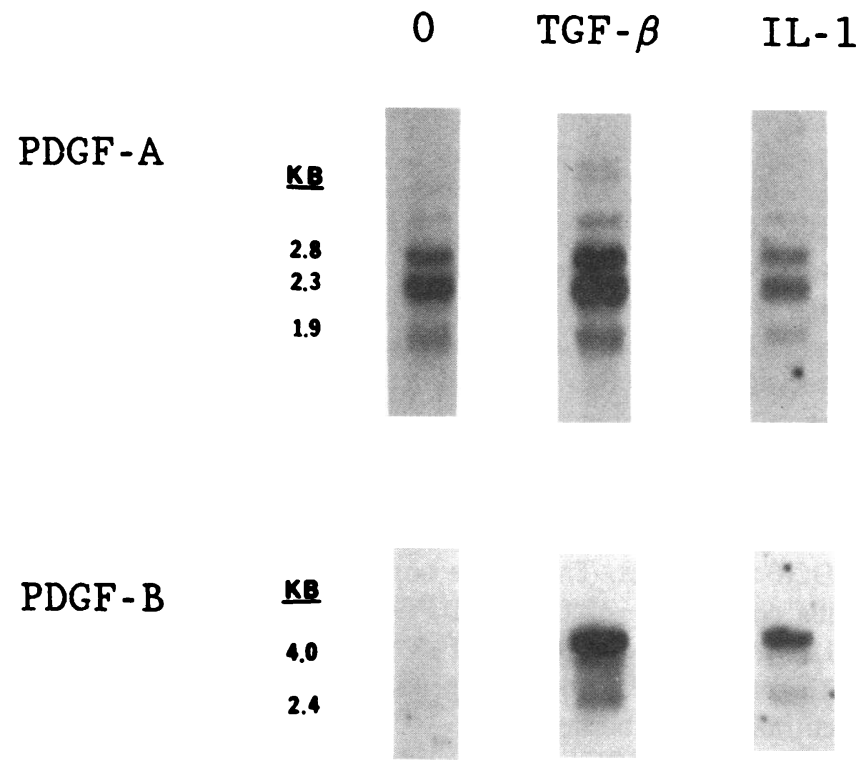

Figure 1. The modulation of PDGF mRNA expression in normal human keratinocytes. Normal human keratinocytes were cultured in $\mathrm{KBM} \pm 10 \mathrm{ng} / \mathrm{ml} \mathrm{TGF}{ }_{\beta}, 10 \mathrm{U} / \mathrm{ml}$ recombinant human $\mathrm{IL}-1_{\alpha}$ for 12 h. PDGF-A and PDGF-B mRNA expression was determined by Northern blot analysis.

conditioned media samples, low levels of PDGF-AA and BB, and elevated levels of PDGF-AB were detected in detergent extracts of keratinocytes grown in $\mathrm{KBM}$ alone or $\mathrm{KBM}$ supplemented with either IL- $1_{\alpha}$ or $\mathrm{TGF}_{\beta}$.

Detection of PDGF mitogenic activity in keratinocyte-conditioned culture media. To demonstrate that the PDGF-AA detected by ELISA and Western blot has functional biologic activity, keratinocyte-conditioned culture media was concentrated, then analyzed for the ability to stimulate $\left[{ }^{3} \mathrm{H}\right]-$ thymidine incorporation into murine 3T3 cells. This cell type has been shown to respond mitogenically to all three PDGF isoforms ( $\mathrm{AA}, \mathrm{AB}, \mathrm{BB})$ (12). The concentrated media stimulated a 10 -fold increase in $\left[{ }^{3} \mathrm{H}\right]$ thymidine incorporation over

Table I. Detection of PDGF in Keratinocyte-conditioned Media and in Detergent-solubilized Cell Extracts

\begin{tabular}{lcccccc}
\hline & \multicolumn{3}{c}{ Media } & & \multicolumn{3}{c}{ Extract } \\
\hline Sample & AA & BB & AB & AA & BB & AB \\
Control & 0.84 & ND & ND & 0.14 & 0.80 & 3.27 \\
IL-1 $_{\alpha}$ & 0.88 & ND & ND & 0.20 & 0.61 & 3.95 \\
TGF $_{\beta}$ & 1.58 & ND & ND & 0.14 & 0.64 & 4.50 \\
& & & & & & \\
\hline
\end{tabular}

Human keratinocytes were cultured in 100 -mm dishes in either KGM alone (control), or KGM supplemented with $10 \mathrm{ng} / \mathrm{ml}$ of IL- $1_{\alpha}$ or $\mathrm{TGF}_{\beta}$. After $24 \mathrm{~h}$ the conditioned media was harvested $(10 \mathrm{ml})$, then concentrated 10-fold using a Centriprep-10 (Amicon, Beverly, MA) concentrator. Cells were washed with PBS, then extracted with $1 \mathrm{ml}$ of radioimmunoprecipitation buffer on ice. Both the media concentrates and cell extracts were then analyzed by ELISA for the presence of the individual PDGF isoforms as described in the materials and methods. The data are presented as nanograms per milliliter of PDGF measured in the concentrated media and in the cell extract. The sensitivity of detection for PDGF-BB and $A B$ is 0.036 and $0.15 \mathrm{ng} / \mathrm{ml}$, respectively. ND, not detectable. 
background. This stimulation was partially inhibited by the addition of a neutralizing monoclonal antibody to PDGF-AA, 127.222 , as well as polyclonal rabbit anti-PDGF A chain IgG (Fig. 2). Addition of rabbit anti-PDGF B chain had no inhibitory effect on either the keratinocyte culture media or on purified PDGF-AA.

These results demonstrate that PDGF-AA present in keratinocyte-conditioned culture media is mitogenically active. They also support the findings that there are no significant levels of PDGF-AB or BB in the keratinocyte media, due to the lack of inhibitory activity by the rabbit anti-PDGF $B$ chain antibody. Clearly there are additional mitogens for the 3T3 cells in the keratinocyte media as demonstrated by the limited neutralization of $\left[{ }^{3} \mathrm{H}\right]$ thymidine incorporation by the antiPDGF antibodies. The media concentrate added to the 3T3 cells contained $\sim 2.0 \mathrm{ng} / \mathrm{ml}$ PDGF-AA, as determined by ELISA. This amount of PDGF-AA corresponds to the level of mitogenic stimulation that was inhibited by the two PDGF-AA neutralizing antibodies.

Analysis of PDGF receptor expression in keratinocytes. To determine if PDGF might be functioning in an autocrine fashion in human keratinocytes, we monitored for the presence of PDGF receptors in these cells. Direct cell-surface expression studies were done with monoclonal antibodies PR292 and PR7212. These antibodies recognize extracellular epitopes on the PDGF alpha and beta receptors, respectively. The binding of these antibodies was monitored on both keratinocytes and human dermal fibroblasts. To demonstrate binding specificity of the antibodies to the PDGF receptors, the test cells were first incubated at $37^{\circ} \mathrm{C}$ with $50 \mathrm{ng} / \mathrm{ml}$ of PDGF-BB for increasing lengths of time to stimulate receptor downregulation. Treat-

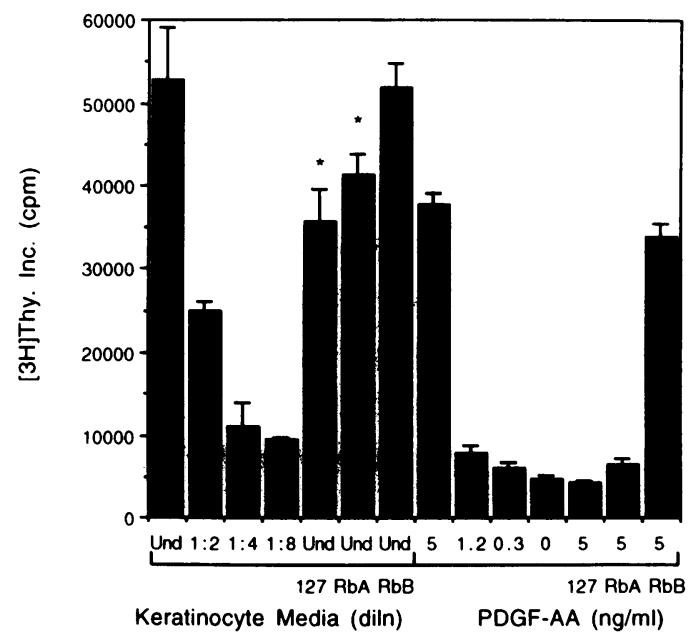

Figure 2. Detection of PDGF-AA mitogenic activity in keratinocyteconditioned culture media. Increasing amounts of purified PDGF-AA and dilutions of concentrated keratinocyte conditioned culture media were analyzed for mitogenic activity by the ability to stimulate $\left[{ }^{3} \mathrm{H}\right]-$ thymidine incorporation into murine 3T3 cells. Anti-PDGF antibodies 127.222 (127), rabbit anti-PDGF A chain $\operatorname{IgG}(R b A)$, or rabbit anti-PDGF $B$ chain IgG $(\mathrm{RbB})$ were added to $5 \mathrm{ng} / \mathrm{ml}$ of purified $A A$ and to the undiluted keratinocyte concentrate (Und). Both antiPDGF AA antibodies were able to significantly inhibit the mitogenic activity in the conditioned media sample, demonstrating the presence of PDGF-AA, while no inhibitory activity was observed with the anti-PDGF B chain antibody. The results are expressed as cpm of $\left[{ }^{3} \mathrm{H}\right]$ thymidine incorporation $\pm \mathrm{SD}$ for triplicate determinations. ${ }^{*} P<0.05$.

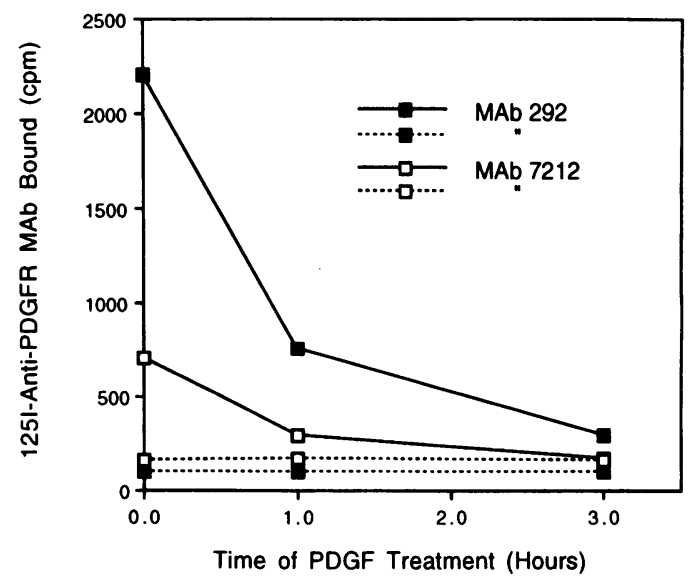

Figure 3. PDGF receptor binding assay. Normal human keratinocytes (dashed lines) and human fibroblasts (solid lines) were grown to near confluence in 24-well culture dishes in KGM, and DME containing $10 \%$ fetal calf serum, respectively. $50 \mathrm{ng} / \mathrm{ml}$ of PDGF-BB was added to the media for increasing lengths of time to stimulate PDGF receptor downregulation. The plates were washed, then incubated with ${ }^{125}$ I-labeled PR292, anti-alpha receptor (solid box), or PR7212, antibeta receptor (open box), for $5 \mathrm{~h}$ at $4^{\circ} \mathrm{C}$. The plates were washed to remove unbound antibody, the cells lysed with $0.1 \mathrm{M} \mathrm{NaOH} / 0.1 \%$ Triton X-100, and the lysates counted in a gamma counter to determine the level of antibody binding. The results are presented as total cpm bound.

ment of fibroblasts with PDGF-BB led to a time-dependent decrease in the binding of both antibody PR292 and PR7212, demonstrating that both PDGF alpha and beta receptors are present on human dermal fibroblasts (Fig. 3). In contrast, the level of antibody binding to the keratinocytes was much lower with no evidence of receptor downregulation after PDGF-BB treatment. The lack of PDGF receptors on keratinocytes was similarly observed on keratinocytes treated for $24 \mathrm{~h}$ with 5 $\mathrm{ng} / \mathrm{ml}$ of either IL- $1_{\alpha}$ or $\mathrm{TGF}_{\beta}$ (data not shown). These results indicate that keratinocytes in culture do not express detectable levels of PDGF receptor polypeptide.

To determine if keratinocytes might express mRNA for the PDGF alpha and beta receptors, but fail to make polypeptide detectable by the two antireceptor antibodies, Northern blot analysis was done on poly-A-selected mRNA isolated from cultured human keratinocytes. The Northern blot analysis showed no detectable levels of mRNA for either the alpha or beta receptor, while mRNA isolated from human dermal fibroblasts showed high levels of expression of a 6.4-kb transcript for the alpha receptor and a 5.5-kb transcript for the beta receptor (Fig. 4). Equal loading of mRNA in all lanes of the Northern blot was confirmed by ethidium bromide staining and actin mRNA determinations (data not shown). The lack of PDGF receptor expression by cultured keratinocytes was further confirmed by PCR analysis (data not shown).

Immunostaining of PDGF in human skin. To determine if keratinocytes express PDGF in vivo, cryosections of normal human skin were stained with monoclonal antibodies specific for the A and B chains of PDGF. Staining of the epidermis was observed with monoclonal antibody 127.573 , which is directed against the PDGF-A chain and detects both PDGF-AA and AB. Staining was present from the basal layer into the granular layer (Fig. $5 A$ ) but was not observed in the cornified layer. This staining was abolished when the antibody was first pread- 
A

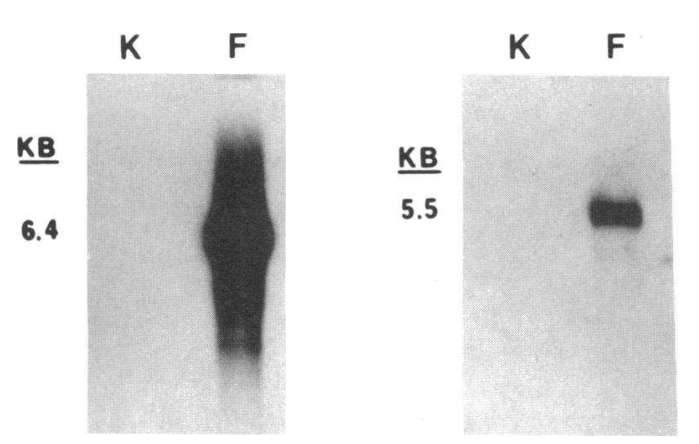

Figure 4. Detection of PDGF receptor mRNA by Northern blot analysis. Poly-A selected mRNA isolated from normal human keratinocytes $(K)$ and human fibroblasts $(F)$ was probed by Northern blot analysis for the presence of $(A)$ PDGF alpha receptor and $(B)$ PDGF beta receptor mRNA.

sorbed with PDGF-AA (Fig. $5 \mathrm{~B}$ ) but not with PDGF-BB (data not shown). A second monoclonal antibody, 127.822, which only recognizes PDGF-AA, showed a similar staining pattern (Fig. $5 \mathrm{C}$ ). The presence of PDGF BB in the epidermis was demonstrated by the staining observed with monoclonal antibody 120.121 , which specifically detects PDGF-BB. Staining with this antibody was similarly observed from the basal layer into the granular layer (Fig. $5 \mathrm{D}$ ), and was blocked for by preadsorption of the antibody with PDGF-BB (Fig. $5 E$ ), but not with PDGF-AA (data not shown). A second monoclonal antibody specific for PDGF-BB, 120.311, demonstrated a simi- lar staining pattern (Fig. $5 F$ ). Thus, both PDGF-AA and BB are present in normal human epidermis. However, the presence of PDGF-AB cannot be evaluated by the antibodies used in this study.

To assess the expression of PDGF in human skin at the site of acute healing wounds, we obtained biopsies of partial thickness incised wounds made with a Simplate II bleeding time device (28). 1-d-old wounds were analyzed for the presence of PDGF by immunostaining using affinity-purified rabbit antiPDGF A chain and anti-PDGF B chain polyclonal antibodies. PDGF A chain was clearly detected in the epidermis adjacent to and away from the wound site in 1-d wounds (Fig. $6 \mathrm{~A}$ ) as well as in the newly reconstituted normal epidermis in older wounds (data not shown). Similar findings were observed with PDGF B chain staining, though the intensity of the staining was greatly reduced from that obtained with the anti-PDGF A chain antibody (Fig. $6 \mathrm{~B}$ ). During the course of wound maturation (days 4-21) there was no detectable upregulation of staining for either PDGF A chain or B chain in the epidermis.

There was a striking difference for the staining of the provisional wound matrix of 1-d wounds by the two antibodies. Strong staining was observed with the anti-PDGF A chain antibody (Fig. $6 \mathrm{~A}$ ) while essentially no staining was observed with the anti-PDGF B chain antibody (Fig. $6 \mathrm{~B}$ ). As the wounds matured (days 4-21) there was a continual decrease in the staining for PDGF-A chain as the provisional wound matrix was replaced by granulation tissue. During this same period there was no significant change in staining for PDGF-B chain in the dermis (data not shown).

Immunostaining of PDGF receptor in human skin. PDGF receptor expression in human skin was monitored by immuno-
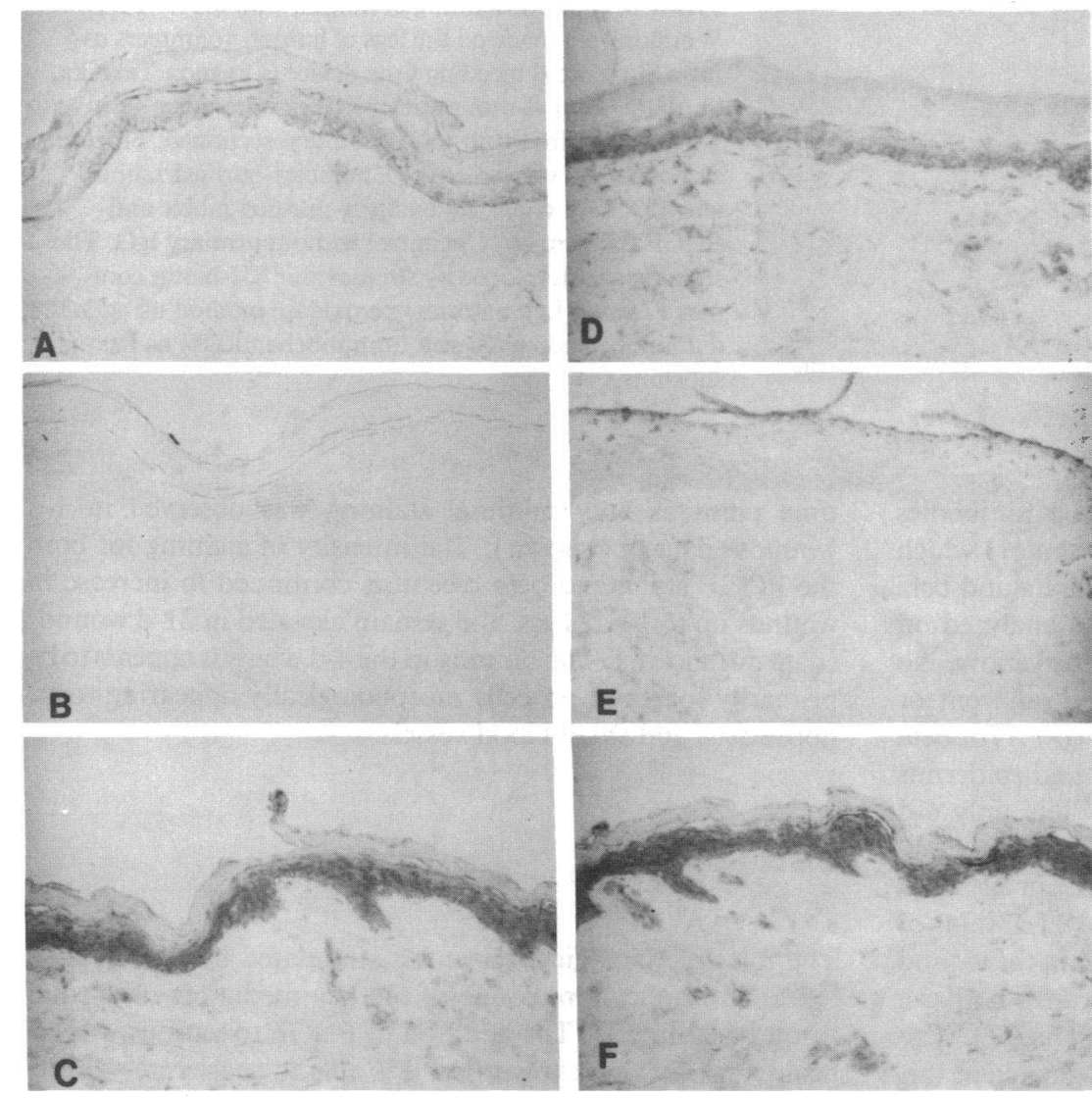

Figure 5. PDGF expression in normal human skin. PDGF-A and PDGF-B peptide expression in normal human skin was determined by immunohistochemistry using PDGF isoform specific monoclonal antibodies. mAbs 127.573 and 120.121 were coincubated with purified PDGF-AA and BB, respectively, to demonstrate antibody binding specificity. The specificity of the individual mAbs is presented in italics $(A)$ 127.573 $A A / A B,(B) 127.573$

+ PDGF-AA, $(C) 127.822 A A,(D) 120.121$ $B B,(E) 120.121+$ PDGF-BB, $(F) 120.311$ $B B$. 

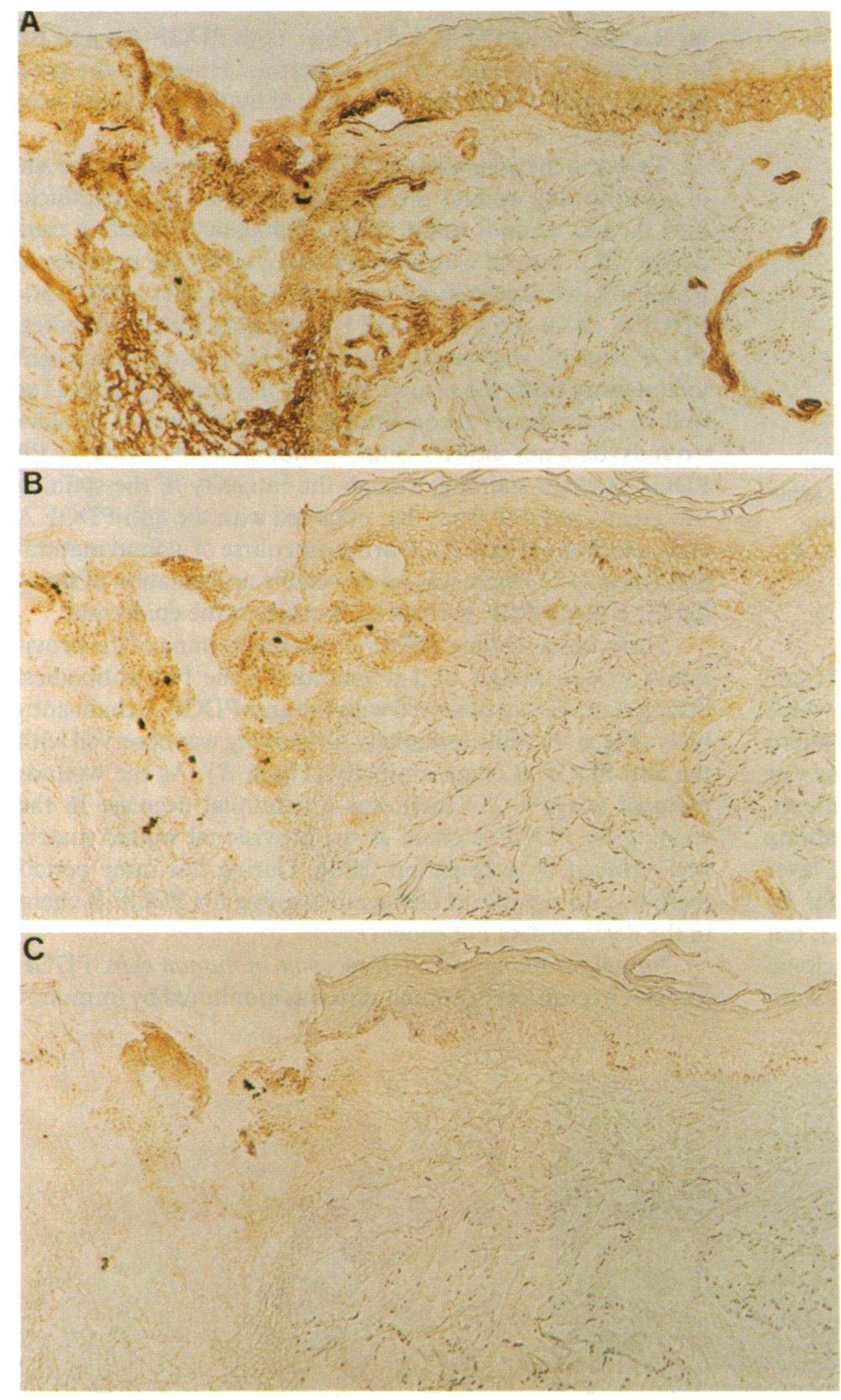

Figure 6. Immunostaining of human wounds for PDGF. Wounds were made on the legs of human volunteers using a Simplate II bleeding time device (Organon Teknika, Durham, NC). 4-mm punch biopsies were taken from $1-\mathrm{d}$ wounds, frozen in OCT, and cryosectioned. Frozen sections were stained with $(A)$ affinity-purified rabbit anti-PDGF $A$ chain, $(B)$ affinity-purified rabbit antiPDGF B chain, or $(C)$ control without primary IgG. The staining was developed by streptavidin AH-biotin complex (Zymed Laboratories) peroxidase method using 3,3 diaminobenzidine (Sigma Immunochemicals) as the substrate. staining using anti-PDGF receptor monoclonal antibodies 169.522 (alpha receptor) and PR7212 (beta receptor) which recognize extracellular epitopes on the PDGF alpha and beta receptors, respectively. Receptor expression was analyzed on cryosections obtained from 4-d wounds as described above. No staining was observed on epidermal cells either adjacent or away from the wound site for either the alpha (Fig. $7 A$ ) or beta receptor (Fig. $7 B$ ). The newly reconstituted wound epidermis was similarly negative for receptor staining. While only 4-d wounds are presented here, similar results showing lack of epidermal staining were observed on wounds ranging in age from 1 to $21 \mathrm{~d}$ (data not shown). In contrast to the lack of staining of the epidermis, strong staining of the dermis, both in the wound bed itself and in the adjacent tissue, was observed for both the alpha and beta receptors on four day wounds (Fig. 7). The staining for PDGF receptors was markedly upregulated at this time point as only minimal staining was observed in 1-d wounds (data not shown). The intensity of staining for both the PDGF alpha and beta receptors continued to increase in wounds up to $14 \mathrm{~d}$ of age and remain elevated in $21-\mathrm{d}$ wounds (data not shown). The staining in the 4-d wounds appears to be primarily localized on cells morphologically appearing to be fibroblasts, and small blood vessels.

\section{Discussion}

The multiple biological responses stimulated by PDGF have led to its implication as one of the key mediators of dermal wound healing (2). The addition of PDGF to various wound healing models has shown that it is able to accelerate various 

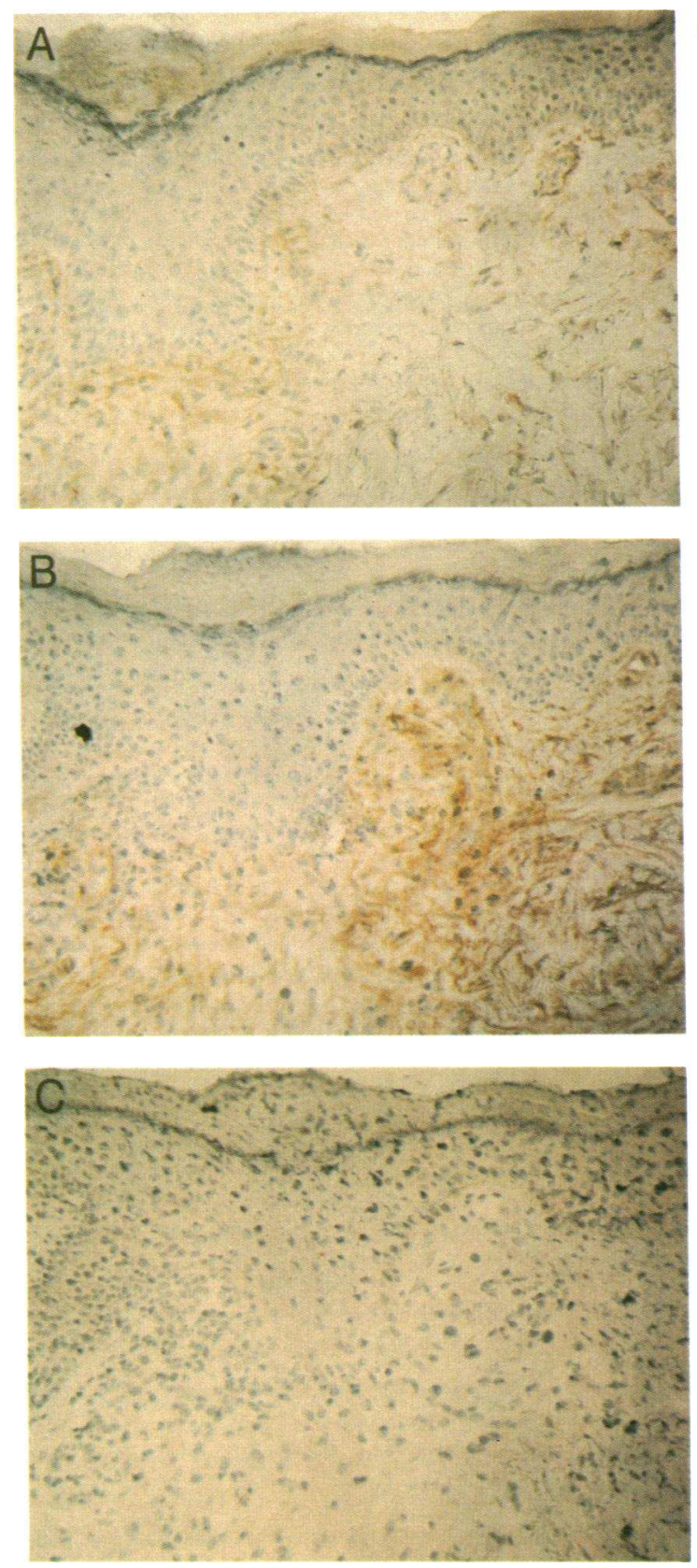

Figure 7. Immunostaining of human wounds for PDGF receptor. Wounds were made on the legs of volunteers using a Simplate II bleeding time device. 4-mm punch biopsies were taken from 4-d wounds, frozen in OCT, and cryosectioned. Frozen sections were stained with $(A)$ mAb169.52 alpha receptor, $(B)$ mAb PR7212 beta receptor, or $(C)$ control without primary IgG. The staining was developed by streptavidin AH-biotin complex (Zymed Laboratories) peroxidase method using 3,3' diaminobenzidine (Sigma Immunochemicals) as the substrate.

aspects of wound healing including reepithelialization and granulation tissue formation $(18,19,29-31)$. This has been shown in both normal animals (29-31) and animals with wound healing impairments, such as $\mathrm{db} / \mathrm{db}$ diabetic mice (18).

Platelets and macrophages that enter into the wound have been proposed as the major sources of PDGF in healing cutaneous wounds. Our studies indicate that keratinocytes in culture produce high levels of PDGF, suggesting that this cell type may also be a major source of PDGF for wound healing in the skin. The identification of PDGF by immunostaining in both nonwounded and in regenerating epithelium strongly support this hypothesis. The source of the PDGF A chain observed by immunostaining in the provisional wound matrix is not clear. However, the detection of only PDGF-AA in the conditioned media of cultured keratinocytes and the presence of mainly PDGF A chain in the provisional wound matrix suggests that the A chain present may be derived from the epidermal cells. This idea is further supported by the knowledge that PDGF present in the alpha granules of human platelets is composed of approximately equal amounts of both PDGF A and B chains (3). Additionally, it has been shown that macrophages in culture express both PDGF A and B chain polypeptide (32). These data support the role of keratinocyte-derived PDGF in cutaneous wound healing.

The finding of constitutive expression of PDGF polypeptide in epidermal cells of both nonwounded and wounded human tissue is in contrast to the findings of Antoniades and co-workers (33) who only detected transient expression of PDGF B chain in the epidermis between 1 and $4 \mathrm{~d}$ after placement of full-thickness wounds in pigs. It is unclear if this discrepancy is due to differences in the detection methods for PDGF or represents a real biologic difference between human and porcine epidermis.

The production of PDGF by human keratinocytes does not appear to function as an autocrine factor in epidermal repair. Neither PDGF receptor polypeptide nor mRNA was detected in cultured human keratinocytes. Additionally, neither PDGF alpha or beta receptor was detected by immunostaining in the epidermis of either normal skin, or in the epidermis of healing human wounds ranging from 1 to $21 \mathrm{~d}$ in age. It has recently been reported by Antoniades and co-workers (33) that there is transient expression, as measured by both in situ hybridization and immunostaining, of PDGF beta receptor in the epidermis of porcine wounds. Again, whether this reflects variation between species or simply differences in detection methods from those reported here is unclear. The identification of functional PDGF receptors has not yet been described in cultured porcine keratinocytes.

Using a panel of monoclonal antibodies to the PDGF receptors we have identified a subset of antibodies which immunostain human keratinocytes both in culture and in skin biopsies. One of the antibodies to the PDGF beta receptor appears to detect a $200-\mathrm{kD}$ cytoplasmic molecule as demonstrated by immunoprecipitation of $\left[{ }^{35} \mathrm{~S}\right]$ methionine labeled cell extracts (data not shown). The finding that this molecule is expressed cytoplasmically, and that its presence is not modified after the addition of either PDGF-AA or BB to cultured keratinocytes (data not shown) suggests that it is not a functional PDGF receptor but that it shares similar antigenic determinants with the PDGF beta receptor. It is possible that the staining observed by Antoniades and co-workers could have been to a similar molecule in porcine keratinocytes.

The detection of only PDGF-AA in the culture media of keratinocytes, although the cells make both PDGF A and B chain mRNA, is consistent with previous findings where only PDGF-AA is efficiently secreted by many cell types (34-36). The PDGF-AA detected in the culture media corresponds in size by Western blot to the short form of A chain (data not shown). The mRNA coding for the short form lacks exon 6 , which is present in the long form of $A$ chain and which codes for a stretch of basic amino acid residues. This stretch of amino 
acids appears to act as a heparin-binding retention sequence to maintain cell association of the long form of PDGF-AA (35, 36). A similar stretch of basic residues is found in the $B$ chain of PDGF $(34,35)$. While only PDGF-AA was detected in the culture media, all three PDGF isoforms ( $A A, B B$, and $A B$ ) were detected in cell extracts. It is interesting to note that elevated levels of $B$ chain mRNA detected in the IL- $1_{\alpha}-$ and $\mathrm{TGF}_{\beta}$-treated cells did not correspond to substantial increases in the production of PDGF B chain protein. Additionally, the PDGF B chain produced appears to be primarily directed into PDGF-AB.

The recent identification that human keratinocytes are a rich source of a wide variety of growth factors necessitates reevaluation of the potential roles played by these cells in cutaneous inflammation and wound healing. In addition to providing a boundary layer for prevention of water loss, and protection against surface abrasion, we now must view keratinocytes as a major source of cytokines which will directly influence adjacent dermal constituents. While we have primarily focused on the potential role of keratinocyte-derived PDGF in acute wound repair in this manuscript, one could speculate for a much broader role for PDGF in skin function. Not only through direct actions on cells within the dermis, but indirectly on the epidermis through the regulation of vascular growth and the subsequent availability of the necessary nutrients.

\section{Acknowledgments}

We wish to thank Dr. Dan Bowen-Pope for the gift of mAb 292.18 and Betty Haldeman for technical assistance.

\section{References}

1. Luger, T. A. 1993. Epidermal cytokines and growth factors. Marcel Dekker, Inc., New York. In press.

2. Ross, R., E. W. Raines, and D. F. Bowen-Pope. 1986. The biology of platelet-derived growth factor. Cell. 46:155-169.

3. Hart, C. E., M. Bailey, D. A. Curtis, S. Osborn, E. Raines, R. Ross, and J. W. Forstrom. 1990. Purification of PDGF-AB and PDGF-BB from human platelet extracts and the identification of all three PDGF dimers in human platelets. Biochemistry. 29:166-172.

4. Hammacher, A., U. Hellman, A. Johnsson, A. Ostman, K. Gunnarsson, B. Westermark, A. Wasteson, and C.-H. Heldin. 1988. A major part of platelet-derived growth factor purified from human platelets is a heterodimer of one $A$ and one B chain. J. Biol. Chem. 263:16493-16498.

5. Hart, C. E., J. W. Forstrom, J. D. Kelly, R. A. Seifert, R. A. Smith, R. Ross, M. J. Murray, and D. F. Bowen-Pope. 1988. Two classes of PDGF receptor recognize different isoforms of PDGF. Science (Wash. DC). 240:1529-1531.

6. Heldin, C.-H., G. Backstrom, A. Ostman, A. Hammacher, L. Ronnstrand, K. Rubin, M. Nister, and B. Westermark. 1988. Binding of different dimeric forms of PDGF to human fibroblasts: evidence for two separate receptor types. EMBO (Eur. Mol. Biol. Organ.) J. 7:1387-1393.

7. Yarden, Y., J. A. Escobedo, W.-J. Kuang, T. L. Yang-Feng, T. O. Daniel, P. M. Tremble, E. Y. Chen, M. E. Ando, R. A. Harkins, U. Francke, et al. 1986. Structure of the receptor for platelet-derived growth factor helps define a family of closely related growth factor receptors. Nature (Lond.). 323:226-232.

8. Gronwald, R. G. K., F. J. Grant, B. A. Haldeman, C. E. Hart, P. J. O'Hara, F. S. Hagen, R. Ross, D. F. Bowen-Pope, and M. J. Murray. 1988. Cloning and expression of a cDNA coding for the human platelet-derived growth factor receptor: evidence for more than one receptor class. Proc. Natl. Acad. Sci. USA. 85:3435-3439.

9. Claesson-Welsh, L., A. Eriksson, A. Moren, L. Severinsson, B. Ek, A. Ostman, C. Betsholts, and C.-H. Heldin. 1988. cDNA cloning and expression of a human platelet-derived growth factor (PDGF) receptor specific for B-chain-containing PDGF molecules. Mol. Cell. Biol. 8:3476-3486.

10. Matusi, T., M. Heidaran, T. Miki, N. Popescu, W. LaRochelle, M. Kraus, J. Pierce, and S. Aaronson. 1989. Isolation of a novel receptor cDNA establishes the existence of two PDGF receptor genes. Science (Wash. DC). 243:800-804.

11. Claesson-Welsh, L., A. Eriksson, B. Westermark, and C.-H. Heldin. 1989. cDNA cloning and expression of the human A-type platelet-derived growth factor (PDGF) receptor establishes structural similarity to the B-type PDGF receptor. Proc. Natl. Acad. Sci. USA. 86:4917-4921.
12. Seifert, R. A., C. E. Hart, P. E. Phillips, J. W. Forstrom, R. Ross, M. J. Murray, and D. F. Bowen-Pope. 1988. Two different subunits associate to create isoform-specific platelet-derived growth factor receptors. J. Biol. Chem. 264:8771-8778.

13. Eriksson, A., C. Rorsman, A. Ernlund, L. Claesson-Welsh, and C.-H. Heldin. 1992. Ligand-induced homo- and hetro-dimerization of platelet-derived growth factor alpha- and beta-receptors in intact cells. Growth Factors. 6:1-14.

14. Hart, C. E., and D. F. Bowen-Pope. 1990. Platelet-derived growth factor receptor: current views of the two-subunit model. J. Invest. Dermatol. 94:53S57S.

15. Seppa, H., G. Grotendorst, S. Seppa, E. Schiffmann, and G. R. Martin. 1982. Platelet-derived growth factor is chemotactic for fibroblasts. J. Cell Biol. 92:584-588.

16. Deuel, T. F., R. M. Senior, J. S. Huang, and G. L. Griffin. 1982. Chemotaxis of monocytes and neutrophils to platelet-derived growth factor. J. Clin. Invest. 69:1046-1049.

17. Narayanan, A. S., and R. C. Page. 1983. Biosynthesis and regulation of type V collagen in diploid human fibroblasts. J. Biol. Chem. 258:11694-11699.

18. Greenhalgh, D. G., K. H. Sprugel, M. J. Murray, and R. Ross. 1990. PDGF and FGF stimulate wound healing in the genetically diabetic mouse. Am. J. Pathol. 136:1235-1246.

19. Robson, M. C., L. G. Phillips, A. Thomason, L. F. Robson, and G. F. Pierce. 1992. Platelet-derived growth factor BB for the treatment of chronic pressure ulcers. Lancet. 339:23-25.

20. Kelly, J., E. Raines, R. Ross, and M. J. Murray. 1985. The B-chain of PDGF alone is sufficient for mitogenesis. EMBO (Eur. Mol. Biol. Organ.) $J$. 4:3399-3405.

21. Hart, C. E., R. A. Seifert, R. Ross, and D. F. Bowen-Pope. 1987. Synthesis, phosphorylation and degradation of multiple forms of the platelet-derived growth factor receptor studied using a monoclonal antibody. J. Biol. Chem. 262:1078010785.

22. Kelly, J. D., B. A. Haldeman, F. J. Grant, M. J. Murray, R. A. Seifert, D. F. Bowen-Pope, J. A. Cooper, and A. Kazlauskas. 1991. Platelet-derived growth factor (PDGF) stimulates PDGF receptor subunit dimerization and intersubunit trans-phosphorylation. J. Biol. Chem. 266:8987-8992.

23. Mushinski, J. F., F. R. Blattner, J. D. Owens, F. D. Finkelman, S. W. Kessler, L. Fitzmaurice, M. Potter, and P. W. Tucker. 1980. Mouse immunoglobulin D: construction and characterization of a cloned gamma chain cDNA. Proc. Natl. Acad. Sci. USA. 77:7450-7409.

24. Rorsman, F., M. Bywater, T. J. Knott, J. Scott, and C. Betsholtz. 1988. Structural characterization of the human platelet-derived growth factor A-chain cDNA and gene: alternative exon usage predicts two different precursor proteins. Mol. Cell. Biol. 8:571-577.

25. Robbins, K. C., S. G. Devare, and S. A. Aaronson. 1981. Molecular cloning of integrated simian sarcoma virus: genome organization of infectious DNA clones. Proc. Natl. Acad. Sci. USA. 78:2918-2922.

26. Feinberg, A. P., and B. Volgelstein. 1983. A technique for radiolabelling DNA restriction endonuclease fragments to high specific activity. Anal. Biochem. 132:6-13.

27. Raines, E. W., and R. Ross. 1985. Purification of human platelet-derived growth factor. Methods Enzymol. 109:749-773.

28. Olerud, J. E., M. L. Usui, and C. E. Hart. 1991. Localization of PDGF and PDGF receptor in human cutaneous wounds. J. Invest. Dermatol. 96:563. (Abstr.)

29. Pierce, G. F., J. E. Tarpley, D. Yanagihara, T. A. Mustoe, G. M. Fox, and A. Thomason. 1992. Platelet-derived growth factor (BB homodimer), transforming growth factor- $\beta 1$, and basic fibroblast growth factor in dermal wound healing: neovessel and matrix formation and cessation of repair. Am. J. Pathol. 140:13751388.

30. Lynch, S. E., J. C. Nixon, R. B. Colvin, and H. N. Antoniades. 1987. Role of platelet-derived growth factor in wound healing: synergistic effects with other growth factors. Proc. Natl. Acad. Sci. USA. 84:7696-7700.

31. Grotendorst, G. R., G. R. Martin, D. Pencev, J. Sodek, and A. K. Harvey. 1985. Stimulation of granulation tissue formation by platelet-derived growth factor in normal and diabetic rats. J. Clin. Invest. 76:2323-2329.

32. Nagaoka, I., B. C. Trapnell, and R. G. Crystal. 1990. Upregulation of platelet-derived growth factor-A and -B gene expression in alveolar macrophage of individuals with idiopathic pulmonary fibrosis. J. Clin. Invest. 85:2023-2027.

33. Antoniades, H. N., T. Galanopoulo, J. Neville-Golden, C. P. Kiritsy, and S. E. Lynch. 1991. Injury induces in vivo expression of platelet-derived growth factor (PDGF) and PDGF receptor mRNAs in skin epithelial cells and PDGF mRNA in connective tissue fibroblasts. Proc. Natl. Acad. Sci. USA. 88:565-569.

34. LaRochelle, W. J., M. May-Siroff, K. C. Robbins, and S. A. Aaronson. 1991. A novel mechanism regulating growth factor association with the cell surface: identification of a PDGF retention domain. Genes \& Dev. 5:1191-1199.

35. Ostman, A., M. Andersson, C. Betsholtz, B. Westermark, and C.-H. Heldin. 1991. Identification of a cell retention signal in the B-chain of PDGF and in the long splice version of the A-chain. Cell Regul. 2:503-512.

36. Raines, E. W., and R. Ross. 1992. Compartmentalization of PDGF on extracellular binding sites dependent on exon-6-encoded sequences. J. Cell Biol. 116:533-543. 